\title{
The Effect of Out-of School Activities on Conceptual Change in Environmental Education*
}

\author{
Cagri Ozturk Demirbas ${ }^{1}$ \\ ${ }^{1}$ Faculty of Education, Ahi Evran University, Kirsehir, 40100, Turkey \\ Correspondence: Cagri Ozturk Demirbas, Faculty of Education, Ahi Evran University, Kirsehir, 40100, Turkey.
}

Received: December 14, 2016

Accepted: January 23, 2017

Online Published: January 23, 2017

doi:10.11114/jets.v5i2.2077

URL: http://dx.doi.org/10.11114/jets.v5i2.2077

*This Project was supported by the Ahi Evran University Scientific Research Projects Coordination Unit supports this project (Project Number: AEÜ- SBA-11-19).

\begin{abstract}
The objective of this study is to determining the change in secondary school students' cognitive structure related to the concepts of environmental problems. There were 21 th grades students of two middle schools in Kirsehir. In this research, the students participated in outdoor activities on environmental education programmes during 5 weekends consecutively. The data of the research were collected via word association test as pre-test and post-test. The conceptual change process was examined in collected data, and their pre-test and post-test results were analysed by using cut-off point. Conceptual network was constituted by using cut-off points. When pre-test and post-test results were compared, it was found that there is a positive shift in students' conceptual change. In addition, when their concept network was examined, it was observed that there is an upturn in the number of answered words in post-test. However, the numbers of the words associated to the keywords in pre-test were limited. Besides, the connections not provided among the concepts in pre-test emerged in post-test which shows that students' independent knowledge related to the keywords is associated in the post-test. Finally, when pre-test and post-test are compared, both are the increased in response words and emergence of the connection shows that qualitative change accompanies to quantitative change. Furthermore, keywords emerged in upper tabs out of post-test results. This specifies that the out-of school activities is successful in creating conceptual structure.
\end{abstract}

Keywords: geography education, cognitive structure, conceptual change, word association test

\section{Introduction}

The extensive usage of technology and volatile environment's trade-off with the problems of production-consumption cycle significantly harm to the human itself. Along with the fact is that, the destruction of the life chain in nature threatens human health, protecting the harmony of nature and maintaining its sustainability became necessarily. The human being started using the concept of sustainability after the scientific work begins to protect environment and keep it clean and green. According to Brundtland (1987), United Nations Environment and Development Commission's definition in 1987, it is said "the human kind has the ability to ensure a maintainable development by meeting his daily requirements without endangering his ability to respond to the next generations' requirements." In developing the life quality of human beings and economic development, taking into consideration the life quality and continuity of green environment and all living beings on earth has a role in sustainable development. In this perspective, establishing a quality life style in harmony with the nature and increasing environmental awareness to protecting nature are critically important. When different curriculums of different lessons are examined (Tanriverdi, 2009; Cebesoy \& Donmez Sahin, 2010; Kaya\& Tomal, 2011), it is observed that it is aim to raise environmental sustainability awareness among students on the level of knowledge related to familiarizing and protecting environment. However, the information is still not well-converted into an operational level that will offer social participation when the literature is reviewed.

In his study examining the current middle school curriculums in terms of sustainable environmental education, Tanriverdi (2009) discovered that learning outcomes in primary school curriculums mostly have the aim of developing knowledge and attitude. He focused that they are inadequate in terms of developing skill, understanding and value. In addition, he states that the curriculums were designed by aiming to protecting the environment where we live, rather than a sustainable environmental education. Within this context, this research was designed to emphasize the using out-of school activities, 
communing-with-nature activities is an obligation in order to reinforce middle school students' knowledge and attitude with skills, understanding and value works within this context of sustainable environmental education.

During the literature reviewed, studies are found $8^{\text {th }}$ grade students' conceptions of environmental problems on primary school level and of environmental problems and its sub-concepts via comics strips (Secgin, Yalvac \& Cetin, 2010; Ersoy and Turkkan, 2010), their attitudes towards environment (Gokce vd., 2007; Aslan, Sagir \& Cansaran, 2008), primary school's sensitivity of environmental education activities (Simsekli, 2004), the effect of nature education on conception and behaviour (Ozdemir, 2010), students' opinions on environmental problems (Meydan \& Dogu, 2008) and environment knowledge (Atasoy \& Erturk, 2008). However, the determination of the change of cognitive structure related to environmental problems and concepts on middle school level via word associating test (WAT) was not encountered. Perceptions of preschool teachers on environmental problems are examined under six different themes as causes, effects, types, measures, worry/pessimism and other in Ozata Yucel ve Ozkan (2016) study. Word association test was used in this study. As both scope and range of age are different, it is thought that the current study will contribute new dimensions and findings in existing literature.

The main reason behind choosing word association test as a data collection tool is that, new concepts are built on the existing concept in constructivist approach. Student makes sense of the world by reconstructing the information that he/she newly learnt by comparing it to the old ones (Ozmen, 2009). In constructivist learning approach, student's prior knowledge is quite important since he/she builds the new information over it. If there is a conceptual error or misunderstanding, it should be observed before starting the new learning and it should continue after learning. The word association tests are decent method in determining misconceptions and showing how the concept is in relation with the other concepts in the mind of an individual. The word association tests are used in order to reveal students' comprehensions at cognitive level and to determine the relations among the concepts in this structure (Bahar et al., 2006; Akman \& Kocoglu, 2016; Atabek-Yigit, 2016; Karatekin \& Elvan, 2016; Kaya \& Tasdere, 2016; Ayaz, Karakas and Sarikaya, 2016).

In word association test, the students put in order the words that come into their minds about the keyword regarding the given subject within certain time duration. It is thought that student's sequential response to any keyword shows semantic closeness/distantness by presenting the relations in this structure. Closeness or distantness presents the distance of two concepts in memory semantically (Bahar \& Ozatli, 2003). Word association test that will be implemented as a pre-test before learning presents the student's knowledge about that subject, his/her cognitive structure and misconception. The word association test that will be replicated after learning occurred has the feature of post-test. By comparing the results of pre-test and post-test, the changes in the student can be observed. It can be exhibited whether the misconception disappeared or whether the new one is added; the level of conceptual change; or the deficiencies in learning. By seeing the frequencies related to the keywords in pre-test and post-test, drawing a conceptual networks which will help to the teachers in controlling all these outputs.

In the conclusion of the literature review, we found that word associating tests are an effective technique in revealing the cognitive structure, determining the conceptual change and determining the misconceptions (Bahar et al. 1999; Bahar, 2001; Bahar \& Ozatli, 2003; Ozatli, 2006; Yalvac, 2008; Ozatli \& Bahar, 2010; Ercan, Tasdere \& Ercan, 2010; Perker, 2011; Timur, 2012; Gunes \& Gozum, 2013; Kurt, Ekici \& Aksu; 2013; Polat, 2013; Dincol Ozgur \& Yilmaz, 2013; Kaya \& Akis, 2015; Karatekin \& Elvan, 2016; Kaya \& Tasdere, 2016). In order to reveal comprehension and observe the change of cognitive structure, this method is commonly used in literature. In some studies, word association test is also used for detection of permanence (Polat, 2013).

The aim of this study is to determine the change in cognitive structures of middle school students regarding the environmental problems. This study was designed by considering especially outdoor activities/practices and fieldworks will make differences in student about the operational level, value, skill, and practices determined as deficiency in programme reviews. Within this context, word association test was used as reliable data collection tool. It was aimed to make suggestions about the conceptual structure and teaching of environmental problems on the level of middle school education.

\section{Method}

\subsection{Model of Research}

Among pre-experimental models, one sample pre-test and post-test design was used in the study. Independent variable (outdoor practices) is implemented on a randomly formed group (Karasar, 2008: 96). In that model, tests are carried out before implementation of an independent variable and after implementation.

\subsection{Participants}

This research was conducted with total 21 randomly selection students including 11 was females' students and 10 male 
students who were 7th grades and studying at Kirsehir city centre Prof. Dr. Erol Gungor Middle School and Cacabey Middle School. The further details of sample size are presented in Table 1. Meanwhile, primary school is defined as a school for children between 6 and 9 years old in Turkey. Also middle school is defined as a school for children between 10 and 13years old in Turkey.

Table 1. Distribution of the study group according to the school and gender

\begin{tabular}{lllll}
\cline { 2 - 4 } Schools & Female & Male & $\mathrm{n}$ \\
\cline { 2 - 5 } & Prof. Dr. Erol Gungor Middle School & 5 & 5 & 10 \\
Cacabey Middle School & 6 & 5 & 11 \\
\cline { 2 - 5 } & Total & 11 & 10 & 21 \\
\hline
\end{tabular}

\subsection{Procedure}

In the research, the students participated in out-of school practices and environmental education programme for 5 weekends consecutively. Within the scope of "Hardworking Bees Live at Peace with the Nature" project, the students participated in outdoor and field practices along with the theoretical information they learned. Before the practice, word association test was carried out and the students completed practices such as Communication Network, a Sea Tale (Drama), I Designed the Best Poster, Let's Make our own Fabric Bag, Biological Diversity Memory Game, I Painted Environmental Pollution, Fish Bone, The Story of Environmental Pollution etc. and they practiced each theme and practice outdoor. In addition, students had the chance to make observations in the process by participating in outdoor works and visits. At the end of the process, word association test (WAT) was applied again as a post-test.

\subsection{Data Collection Tool}

In the word association test (WAT) which is used as data collection tool, 10 keywords were used within the frame of the themes determined within the scope of the project. The project, which is designed in the main phenomenon of the environmental problems, is based on these words and the words are thought as the most important ones for the content. In selecting the words, middle school education curriculum programmes were examined and their convenience was accepted by two field professions and one field educator. Each word was designed to take place in a separate page and ten blanks were left for each keyword. Besides, the students were asked for relevant sentences at the end of the page for each word. The sample for the first keyword is presented below.

\section{Environmental Problems \\ Environmental Problems \\ Environmental Problems \\ Environmental Problems \\ Environmental Problems \\ Environmental Problems \\ Environmental Problems \\ Environmental Problems \\ Environmental Problems \\ Environmental Problems}

Related Sentence

Chosen words were environmental problems: air pollution, water pollution, soil pollution, biological diversity, noise pollution, and magnetic pollution, urbanization, recycling and saving. The students were informed about word association test before the pre-test. After that, word association test was implemented. Sample work was also carried out with students in the process of word association test. In literature, while there are studies in which 30 seconds were granted for each word (Bahar, Johnstone \& Sutcliffe, 1999; Bahar \& Ozatli, 2003; Nakiboglu, 2008; Timur, 2012; Gunes \& Gozum, 2013; Kaya \& Akis, 2015), there are also some studies in which 1 minute is granted (Ercan, Tasdere \& Ercan, 2010; Oner Armagan,2015). In his study on prospective teachers, Kurt (2013) granted 40 seconds for students. 1 minute was granted also in the current study since the sampling and working groups are at secondary school. In above mentioned studies, in which 30 seconds were granted and the study in which 1 minute is granted is at primary school level. And another reason to grant 1 minute in this study is to ensure that the students can write a relevant sentence under each word. Within this time, students wrote the words respectively that they think to be in relation within the keyword.

The reason behind writing keywords, ten times one another is to prevent continuous response risk. Continuous response risk is: if the student does not return to keyword in each concept writing, the probability of student's writing words that 
are brought to his/her mind by the concept he/she write as response in the place of keyword. In order to prevent this risk probability, the keyword is implemented to the students by rewriting in each line. A similar implementation was conducted in the studies of Bahar \& Ozatli (2003) and Polat (2013). In the implementation process a special attention was paid to passing to the other concept when each one's time was over. Attention was shown to ensure that the students write relevant sentence under each keyword. As Nartgun (2006) mentions, relevant sentences were gathered and analysed in order to check whether the response words are related to keywords only on the level of remembering and whether this significance is true or not. At the end of theoretical work, the practical and fieldworks practiced for 5 weekends consecutively, word association test was implemented to the students as post-test.

\subsection{Data Analysis}

In the analysis of data, first of all, the frequency table number of response words given by the students for each concept in pre-test and post-test were formed. For each concept, the increase or decrease at the number of the words used by the students in pre-test and post-test was checked descriptively. In the second step, descriptive analysis table was constituted. The table is related to the mostly repeated first three words for each keyword in pre-test and post-test. In the third step of analysis, concept network drawings related to the pre-tests and post-tests were performed by using the cut-off point (CP) put by Bahar et al. (1999). In this technique, cut-off point is defined according to the number of words that are mostly stated in relation to keywords. However, the number of words answered should be 3-5, less in number than the total in defining cut-off point. Then, the responses found over this frequency are written to the section in the first part of concept network. By lowering to the cut-off point as much as the defined interval, the process is maintained until all the keywords emerge in concept network. Concept network constituted according to pre-test formed in Figure 1 and the concept network formed according to the post-test was constituted in Figure 2 with this technique.

\section{Findings}

In Table 2, the number of words provided by middle school students for each keyword in WAT in pre-test and post-test was presented. The quality and number of the produced words in WAT may be used in revealing manner of understanding about concept and whether it is understood or not.

Since, whether a concept is understood or not is related to the other words that the student associated with (Bahar et al., 2006). In another words, as a concept which is not associated with any word is meaningless in the mind of the student, it can be claimed that the meaning increases as the number of the word associated to the concept increases (Ercan, Tasdere \& Ercan, 2010).

Table 2. Number of words in the responses to for the keywords

\begin{tabular}{llll}
\hline \multirow{3}{*}{ Keywords } & Number of Word & Increasing Word \\
\cline { 2 - 3 } & Pre-test & Post-test & \\
\hline Environmental Problems & 136 & $f$ & 29 \\
Air Pollution & 90 & 165 & 20 \\
Water Pollution & 87 & 110 & 49 \\
Soil Pollution & 89 & 136 & 27 \\
Biological Diversity & 60 & 116 & 63 \\
Noise Pollution & 71 & 123 & 53 \\
Magnetic Pollution & 76 & 124 & 26 \\
Urbanization & 85 & 102 & 35 \\
Recycling & 74 & 120 & 58 \\
Saving & 55 & 132 & 47 \\
\hline Total & 823 & 102 & 407 \\
\hline
\end{tabular}

When the Table 2 was examined, it was found that while total response, word number in pre-test before the implementation is 82 , total response word number in post-test after the implementation is 1230 . When number of the words answered related to all keywords are analysed and upturn is observed. The most upturn is related to keyword called biological diversity in number 63, the least increase is related to keyword called air pollution in number 20 . The increase in words from most to least is as in the following: biological diversity (63), recycling (58), noise pollution (53), water pollution (49), saving (47), urbanization (35), environmental problems (29), soil pollution (27), magnetic pollution (26) and air pollution (20). After the implementation, it is seen that there is a rise in the number of the words as 407. Within this scope, it can be said that there is an increase in understanding and comprehension of the keywords at the end of implementation. In addition, according to the pre-test results, it was found that the students have the least number of answered words on the concepts of saving (55) and biological diversity (60), and they have the highest number of answered words related to the concept of environmental problems (136).

The mostly stated top three responses for each concept and their number are presented in table 3 . Within this scope, the frequently expressed link is created by students between which words and keywords in pre-test and post-test will be studied. 
Table 3. Students' first three words and numbers of words regarding each of keywords

\begin{tabular}{|c|c|c|c|c|c|c|c|}
\hline Keywords & $\begin{array}{l}\text { Test } \\
\text { Type }\end{array}$ & $1 \mathrm{st}$ & $\begin{array}{l}\text { Number } \\
\text { of Word }\end{array}$ & $2 \mathrm{nd}$ & $\begin{array}{l}\text { Numb } \\
\text { er of } \\
\text { Word } \\
\end{array}$ & $3 \mathrm{rd}$ & $\begin{array}{l}\text { Number } \\
\text { of Word }\end{array}$ \\
\hline Environmental & Pre-test & Pollution & 12 & Air Pollution & 9 & Rubbish & 9 \\
\hline Problems & Post-test & Soil Pollution & 15 & Water Pollution & 13 & Air Pollution & 12 \\
\hline \multirow{2}{*}{ Air Pollution } & Pre-test & Fume & 8 & Exhaust & 7 & Filter & 6 \\
\hline & Post-test & Filter & 12 & Exhaust & 9 & Smokestack & 6 \\
\hline \multirow{2}{*}{ Water Pollution } & Pre-test & Dead Fish & 22 & Factories & 9 & Sea & 8 \\
\hline & Post-test & Fish & 12 & Waste & 11 & Trash & 10 \\
\hline \multirow{2}{*}{ Soil Pollution } & Pre-test & Beetle & 18 & Rubbish & 9 & Plant & 7 \\
\hline & Post-test & Plant & 13 & Waste & 11 & Rubbish & 10 \\
\hline Biological & Pre-test & Animals & 7 & Plant Species & 5 & Species & 5 \\
\hline Diversity & Post-test & Plant & 14 & Species & 8 & Ecosystem & 7 \\
\hline \multirow{2}{*}{ Noise Pollution } & Pre-test & Voice & 6 & Car Horn & 5 & Car & 5 \\
\hline & Post-test & Noice & 13 & Car & 8 & Speaker & 7 \\
\hline Magnetic & Pre-test & Radiation & 14 & Telephone & 7 & Computer & 6 \\
\hline Pollution & Post-test & Radiation & 15 & Computer & 5 & Television & 4 \\
\hline \multirow[t]{2}{*}{ Urbanization } & Pre-test & Shanty & 7 & $\begin{array}{l}\text { Unplanned } \\
\text { Urbanization }\end{array}$ & 5 & City & 4 \\
\hline & Post-test & Shanty & 10 & Apartment Block & 7 & House & 6 \\
\hline \multirow{2}{*}{ Recycling } & Pre-test & Glass & 11 & Paper & 11 & Plastic & 10 \\
\hline & Post-test & Plastic & 21 & Glass & 18 & Paper & 17 \\
\hline \multirow{2}{*}{ Saving } & Pre-test & Money & 9 & Water & 8 & Electric & 7 \\
\hline & Post-test & Water & 15 & Electric & 13 & Money & 8 \\
\hline
\end{tabular}

The words stated by middle school students for each keyword both in pre-test and post-test are overlap. In addition, answered words are the necessary ones for the comprehension of keywords. It is discovered that neither in pre-test nor in post-test were the meaningless words used. Although places of the answered words for recycling and saving keywords in pre-test and post-test are changed, they did not differentiate. In pre-test and post-test, each of the keywords soil pollution, air pollution, noise pollution and magnetic pollution has two similar answered words while the keywords environmental problems, water pollution, biological diversity, and urbanization have just one.

According to pre-test and post-test, the results are related to the associated answered words and keywords in interpreted frequency table has been mentioned before, and the conceptual network was created. The pre-test concept network out of the responses stated by secondary school students and the comments in relation to this network are presented in Figure 1.

BP 16 and above

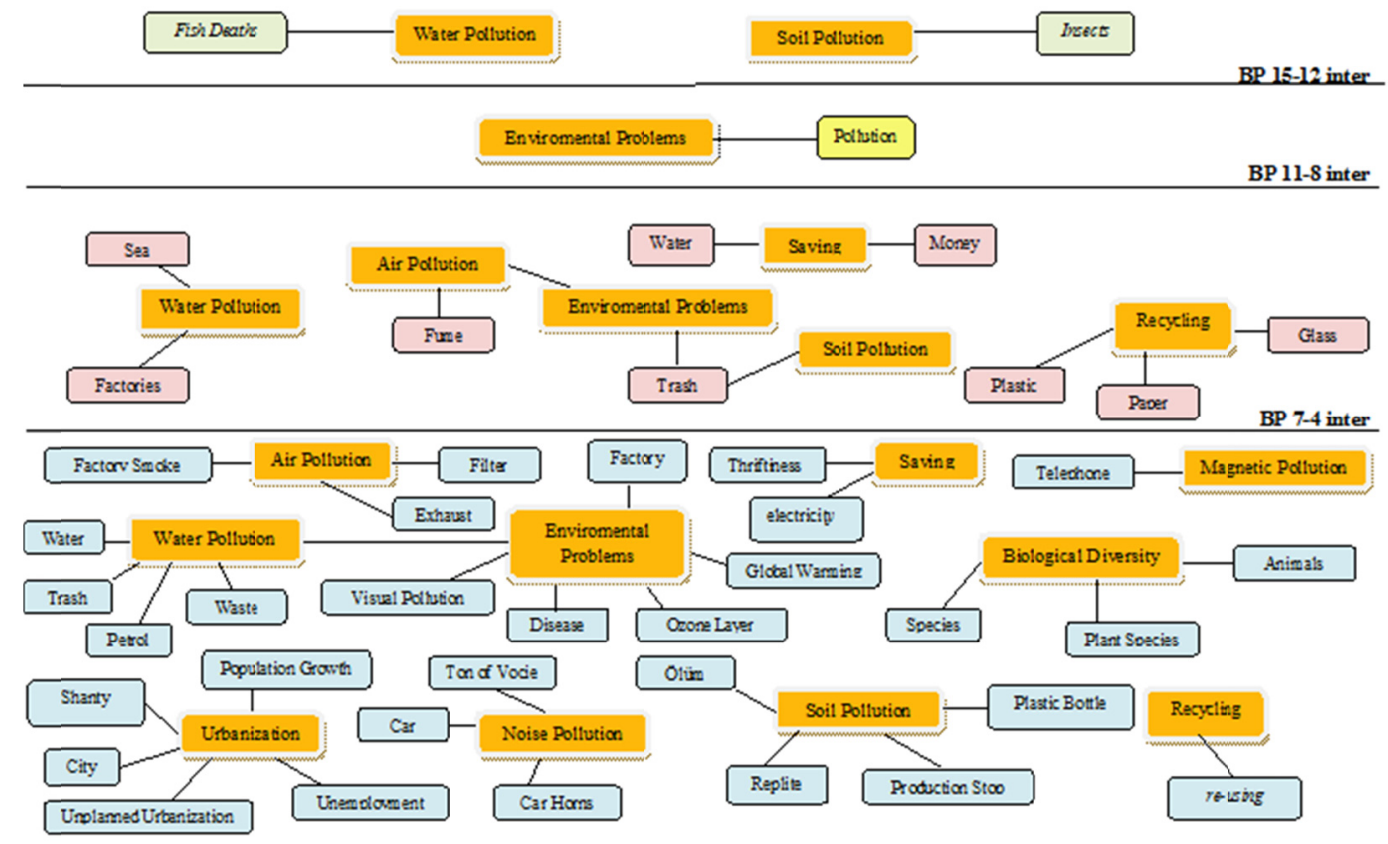

Figure 1. Pre-test concept network

- The fact that middle school students could answer only two of 10 keywords in $\mathrm{BP} \geq 16$ level can be interpreted; as they do not have adequate knowledge on environmental problems and its sub-concepts. When the schedule that 
students participated before the implementation is considered, students are expected to have learned some of these basic concepts on development or reinforcement level. In the frequency table prepared on this cut-off point, it is observed that students came up with words that are related to only water pollution and soil pollution concepts. Students associated insects $(f=22)$ response word for the keywords of water pollution, fish deaths $(f=18)$ and soil pollution concept. Although environmental problems, one of the keywords are a central concept for overall subject, students did not mention it in tab. Actually the fact is that, they did not state any response for environmental problems and they only mentioned two of the keywords shows that they do not have sufficient knowledge. In addition, it is discovered that they did not connect a network among the concepts and they considered them independent from each other.

- For BP within the range 12-15, only the environmental problems, which are one of the keywords of the field subject, are revealed. However, in that tab middle school students matched this concept not with other keywords but only with pollution $(f=12)$ keyword. In this scenario, it is observed that the students cannot come up with a network in this tab among the concepts on pre-test level. As a matter of fact, the keywords that emerged in the upper tab are not seen in this tab.

- For BP within the range 8-11, it is observed that 6 keywords emerged and there was a direct and indirect network with one of these concepts. In this tab, water pollution, soil pollution, environmental problems, saving, air pollution and recycling keywords are revealed. While students established a direct network between environmental problems central concept and air pollution keyword, they established an indirect network between soil pollution keyword and the word of trash. It is discovered that students structure main concept, water pollution with sea $(f=8)$ and factories $(f=9)$; air pollution keyword with fume $(f=9)$; environmental problems keyword with trash $(f=10)$ and air pollution $(f=9)$; soil pollution keyword with trash $(f=9)$; saving keyword with money $(f=9)$ and water $(f=9)$; recycling keyword with glass $(f=11)$, paper $(f=11)$ and plastic $(f=10)$ words.

- For BP 4-7, it is observed that all keywords are revealed but only an islet is generated among the keywords and there is not a network among other 8 keywords. That shows the concepts are structured disconnectedly in prior knowledge. There is only one network between key concept called environmental problems and water pollution. When the interpretation of the concepts are examined, it is observed that the students structured water pollution keyword with waste $(f=6)$, water $(f=5)$, trash $(f=4)$ and petrol $(f=4)$; environmental problems key word with water pollution $(f=7)$, factory $(f=6)$, visual pollution $(f=4)$, disease $(f=4)$, ozone layer $(f=4)$ and global warming $(f=4)$; air pollution key word with exhaust $(f=7)$, filter $(f=6)$ and factory smoke $(f=4)$; soil pollution key word with death $(f=6)$, reptile $(f=6)$, production stop $(f=6)$ and plastic bottle $(f=5)$; biological diversity key word with animals $(f=6)$, species $(f=5)$ and plant species $(f=4)$; noise pollution key word with tone of voice $(f=6)$, car $(f=4)$ and car horns $(f=4)$; magnetic pollution key word with telephone $(f=4)$; urbanization key word with shanty $(f=7)$, unplanned urbanization $(f=6)$, unemployment $(f=6)$ and city $(f=4)$; recycling key word with re-using $(f=4)$; saving key word with electricity $(f=7)$ and thriftiness $(f=6)$. In this cut-off point, the response words had significance scientifically. However, the case of not emergence of these response words in the upper cut-off points can be interpreted as majority of students do not have this information. No matter how each keyword is revealed in this cut-off point, it can be interpreted that the students' prior knowledge before study is inadequate for the reasons that network could not be established among keyword and most of the keywords directly related to the subject could not be produced by the students. Besides, it should be focused that they could not establish islets in their structuring. The reason behind provided relations among keywords in pre-test can be stated that students wrote the keywords they saw in each page as response word to the keyword in the next page.

The results of renewed word association test performed after out-of school practices and fieldworks and the last drawn test concept network are presented in Figure: 2.

- On $\mathrm{BP} \geq 16$ level, the primary school students could only create response for recycling key word among 10 key words after the practice. While this key word was among BP 8-11 tab in pre-test, it upgraded two tabs after the practice. In this tab, it is found that the students structured recycling key word with the words of plastic (21), glass $(f=18)$ and paper $(f=17)$.

- For BP 12-15, eight keywords are revealed. In pre-test, there were six keywords even in 7-14 cut-off point in pre-test. That shows there is a positive change in the students in terms of numbers. Besides, a network was created a network among four main concepts, three of which are direct and two indirect concepts. In pre-test there was a relationship in 7-4 tab and these relationships were weaker in terms of both quantity and quality. This situation shows that the conceptual change developed both quantity and quality. In this tab, while an islet is formed directly with environmental problems and air pollution, water pollution and soil pollution concepts, an islet is formed indirectly with biological diversity concept. In addition, it can be said that the structure is scientifically correct since the response words associated with the concepts are the necessary ones in order to understand the concept. 


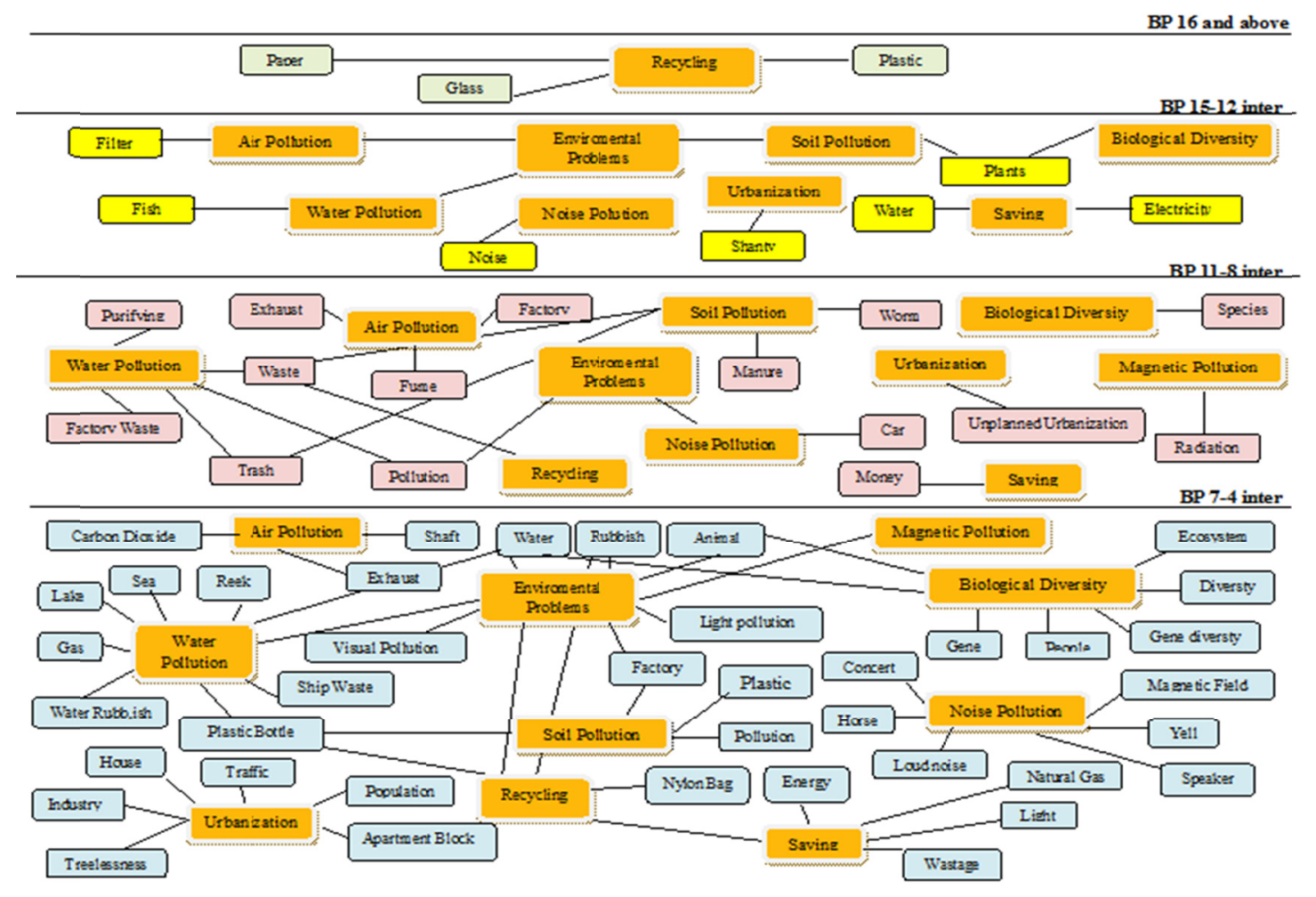

Figure 2. Post-test concept network

- All keywords for BP 8-11 came up. This situation is revealed between cut-off points 4-7 in pre-test. Besides, islet-shaped networks were formed by sharing more than one response words among eight keywords. When the response words are studied, it is observed that the conceptual change developed both in terms of quantity and quality. Especially all response words were scientifically significance and networks' gradual development proves that there is also a structural change.

- Network was created among seven keywords for BP 4-7. Although it did not take place in pre-test, lots of words are used in post-test. These words have the quality of explaining the concepts scientifically. Only the horse response word is directly associated with noise pollution.

When the pre-test and post-test are compared, both the increase in response words and the emergence of networks show that qualitative change accompanies to quantitative change. Furthermore, the keywords are revealed in upper tabs. This shows that the outdoor practices are successful in creating the conceptual structure.

Students' sentences formed in relation to the keywords were examined as well. The sentences were categorized and encoded by taking into consideration information and meanings they include. While the categories were formed, Ercan, Tasdere and Ercan (2010) study was benefited from. Relevant sentences were divided into three categories including, scientific information, non-scientific information, and the misconception. The scientific accuracy and their relation to the keywords of the sentences formed by the students were considered in the category of the ones including scientific information. In the category of the ones including non-scientific information, the ones that the students could not associate to the response words and the ones not state scientifically meaningful but having daily language were placed. In the category of the misconception, the scientific errors and misconceptions in the sentences of the students; if there is were placed. In addition, if the relevant sentence had not been written, it is categorized as empty.

When the relevant sentences formed by the students in relation to the keywords in pre-tests and post-tests are examined, it is observed that there is a numerically positive progress in conceptual change. While 71 sentences including scientific information were formed in pre-test, this number increased to 102 in post-test. While the sentences that are not scientific and including superficial information were 92 in pre-test, they are 103 in post-test. While there were 31 sentences including misconception in pre-test, this number decreased to 3 in post-test. It is seen that the sentences including misconception, in pre-test turned into the sentences including superficial information and scientific information. This shows that the learning improves qualitatively. 
Table 4. Pre-test and post-test frequencies of students' sentences related to keywords

\begin{tabular}{|c|c|c|c|c|c|c|c|c|}
\hline \multirow[t]{2}{*}{ Keywords } & \multirow{2}{*}{$\begin{array}{l}\begin{array}{l}\text { Containing } \\
\text { information }\end{array} \\
\text { Pre-test } \\
\end{array}$} & \multirow{2}{*}{$\begin{array}{l}\text { scientific } \\
\text { Post-test } \\
\end{array}$} & \multicolumn{2}{|c|}{ Superficial Knowledge } & \multicolumn{2}{|c|}{$\begin{array}{l}\text { Containing } \\
\text { Misconceptions }\end{array}$} & \multicolumn{2}{|l|}{ Empty } \\
\hline & & & Pre-test & Post-test & Pre-test & Post-test & Pre-test & Post-test \\
\hline $\begin{array}{l}\text { Environmental } \\
\text { Problems }\end{array}$ & 10 & 11 & 6 & 10 & 5 & - & - & - \\
\hline Air Pollution & 9 & 14 & 11 & 7 & 1 & - & - & - \\
\hline Water Pollution & 13 & 15 & 5 & 6 & 3 & - & - & - \\
\hline Soil Pollution & 6 & 10 & 9 & 10 & 5 & - & 1 & 1 \\
\hline Biological Diversity & 3 & 8 & 8 & 13 & 6 & - & 4 & - \\
\hline Noise Pollution & 5 & 10 & 14 & 10 & 1 & 1 & 1 & - \\
\hline Magnetic Pollution & 7 & 12 & 9 & 8 & 4 & 1 & 1 & - \\
\hline Urbanization & 6 & 9 & 8 & 10 & 3 & 1 & 4 & 1 \\
\hline Recycling & 7 & 6 & 10 & 15 & 1 & - & 3 & - \\
\hline Saving & 5 & 7 & 12 & 14 & 2 & - & 2 & - \\
\hline Total & 71 & 102 & 92 & 103 & 31 & 3 & 16 & 2 \\
\hline
\end{tabular}

While the students left 16 relevant sentence blanks empty in pre-test; there were just 2 empty sentences left in post-test. The fact that the students could not form a significant sentence related to the keywords may be indicating that they could not learn those concepts significantly (Ercan, Tasdere \& Ercan, 2010). Within this context, it can be said that the students structured some keywords in post-test while they could not perform significant structuring in pre-test. In general, Table 4 point out that students' misconception related to the keywords was cleared and the conceptual change came scientifically true.

Although the students participating in the study were expected to learn and structure the concepts used in research because those concepts are placed in the curriculums practiced at their own schools before, it is seen that education at schools related to concepts is not efficient in terms of both correlation and cognitive structuring of the concepts. Out of post-test results, it can be understood that out-of school learning practices and fieldworks are more effective in cognitive structuring and correlation among concepts.

\section{Discussion and Results}

With the effect of constructivist approach on the curriculum of our country, the evaluation step of the learning started to differentiate. In addition to the traditional assessment and evaluation approaches, alternative ones are started to be used. Alternative assessment and evaluation instrument increases the motivations of students in the lesson. Moreover, thanks to alternative assessment instrument by using different projects and presentations; the cognitive structures, conceptual changes and effective learning can be evaluated while the students are presenting their skills which cannot measured with the traditional tests (Hodges, Lamb, Brown \& Foy, 2005). Furthermore, while the traditional measurement instrument is focused on who can and who cannot pass the course. The alternative assessment instrument purposes to check how much gains are achieved, or to check the misconceptions. If they are not attained, and if the reason for this is obtained, within this scope, in order to observe the change related to the environmental problem concepts in this study and to reveal the conceptual structure, word association test was used.

Based on the findings acquired by the pre-test and post-test results, it is proved that the word association test can be used in checking conceptual change. The increase in the word number used in pre-test and in post-test shows that there is a development in the comprehension and structuring of the keywords. In addition, it is determined that pre-test results that primary school students have the least number of response words in relation to saving (55) and biological diversity among keywords, and the most in environmental problems. When the post-test is examined, it is revealed that the primary school students have the least number of response words in relation to magnetic pollution (102) and saving (102) and the most in environmental problems (165), water pollution (136) and recycling (132) concepts. While the least number of response words are in saving keyword in pre-test and post-test. There is two times increase in this key word. By using the word association test, teachers can observe how many the students conceptual knowledge store changed quantitatively.

There is not a study in literature to checking the similar concepts in equivalent age groups. However, in the study in which teachers' opinions on biological diversity are collected through word association test, it is proved that candidate teachers' concepts on biological diversity concepts are concentrated on species diversity, ecosystem, ecology concepts and they have a limited prior knowledge in terms of biological diversity (Uzun, Ozsoy \& Keles, 2010). This supports the findings grasp from this study. There is a study carried out with prospective of preschool education teacher in order to find out their perceptions on environmental problems. Word association test was used. Prospective teachers' perceptions were categorized as causes, effects, types, measures, worry/pessimism and others. It is found out that prospective teachers had a more developed cognitive structure about the reasons of environmental problems in comparison to other themes (Ozata Yucel \& Ozkan; 2016). 
The first three response words of students for every concept are measured. It is observed that the response words having the highest level of frequency do not change. This reveals that new words were added to the conceptual change but the construction was made over the existing words in mind. In simple words, it is in constructivist learning, the new information was incorporated into the existing one.

When the concept networks of pre-test and post-test are compared, it is proved that while all keywords are revealed in 4-7 cut-off points in pre-test, they are revealed in 8-11 cut-off points in post-test. The emergence of all keywords in the one upper tab shows that the conceptual structures enhance significantly also the increase in response words. In pre-test concept network, the network was created only between environmental problems and water pollution keywords. This proves that the students could not establish a connection among the concept words in relation to the subject at the beginning. In post-test concept network, it is observed that there is a connection among eight keywords and islets are constituted among the concepts. These islets indicate that secondary school students also established the connections among the keywords, and they are structured other sub-keywords by associating them under the key concept of environmental problems. However, the existence of the concepts that were not associated in the post-test shows that the learning is not completed. That proves word association test is a decent assessment instrument also in terms of noticing the deficient parts of the subject.

The results of the study supports that word association test should be used in checking whether the misconceptions are cleared or not. When the relevant sentences are examined, it is observed that while the students have 31 sentences including misconception, they have 3 in post-test. Additionally, the number of the sentences including scientific information increased from 71 to 102. As the other studies in the litterateur (Bahar et al, 1999; Cardellini \& Bahar, 2000; Bahar \& Ozatli, 2003; Ozatli, 2006; Yalvac, 2008; Ercan, Tasdere \& Ercan, 2010; Uzun, Ozsoy \& Keles, 2010; Perker, 2011; Kirtak Ad \& Demirci, 2012; Polat, 2013) these findings support that word association test can be used by teacher as diagnostic tool during learning and the conceptual change can be controlled.

According to the our first finding, what is actually valuable in this study is the students, who are expected to have already learnt concepts related to environmental problems within the scope of curriculum did not still accomplish the gains. Another important outcome is that extracurricular learning affects the change in cognitive structure significantly when post-test findings are taken into consideration. Within this context, the network in the pre-test indicates that the students both performed a low level of quantitative structuring and structured concepts independently from each other. When the post-test concept network is examined, it is revealed that the practice carried out is important in terms of students' establishing a relation among the concept along with the quantitative change. In this sense, extracurricular practice and fieldworks importance in terms of environmental education should be emphasized again. In-class learning can be increased in level by adding visuals in encoding the cognitive structure of the concepts.

\section{References}

Akman, O., \& Kocoglu, E. (2016). Investigation 8th grade students secondary school cognitive structure about principles of Ataturk through word association test. Journal of Education and Training Studies, 4(11), 151-162. https://doi.org/10.11114/jets.v4i11.1696

Aslan, O., Sagir, S. U., \& Cansaran, A. (2008). The adaptation of environment attitude scala and determination of primary school students' environmental attitudes. Selcuk University Journal of Ahmet Kelesoglu Education Faculty, 25, 283-295.

Atabek-Yigit, E. (2016). Investigating cognitive structures in some basic chemistry concepts via word association test. Elementary Education Online, 15(4), 1385-1398.

Atasoy, E., \& Erturk, H. (2008). A field study about environmental knowledge and attitudes of elementary school students. Erzincan University Journal of Education Faculty, 10(105-122).

Ayaz, E., Karakas, H., \& Sarikaya, R. (2016). Class teacher candidates' opinions on the concept of nuclear power: the sample of independent word association test. Cumhuriyet Science Journal, 37, 42-54.

Bahar, M. (2001). A critical approach to the multiple-choice test and other methods. Educational Sciences: Theory \& Practice (ESTP), 1(1), 23-38.

Bahar, M., \& Ozatli, N. S. (2003). The investigation secondary school 1th grade students' cognitive structure about basic components of creatures with word association test. Balikesir University, Institute of Science Journal, 5(2), 75-85. (Publishing Turkish).

Bahar, M., Johnstone, A. H., \& Sutcliffe, R. G. (1999). Investigation of students' cognitive structure in elementary genetics through word association tests. Journal of Biological Education, 33, 134-141. https://doi.org/10.1080/00219266.1999.9655653 
Bahar, M., Nartgun, Z., Durmus, S., \& Bicak, B. (2006). Traditional-Alternative Assessment and Evaluation: Teacher's Handbook. Ankara: Pegem Academy Publishing.

Bilici, S. C. (2016). An examination of science teachers' knowledge structures towards technology. International Journal of Environmental and Science Education, 11(5), 571-586.

Brundtland, G. H. (1987), Report of the World Commission on Environment and Development: Our Common Future, UN Documents Gathering a Body of Global Agreements, 20 March 1987, Oslo, http://www.un-documents.net/wced-ocf.htm. (access April 2013).

Cardellini, L., \& Bahar, M. (2000). Monitoring the learning of chemistry through word association tests. Australian Chemistry Resource Book, 19, 59-69.

Cebesoy, U. B., \& Donmez, S. M. (2010). A comparative study of science and technology program in terms of environmental education in middle schools. Research Journal of Biology Sciences, 3(2), 159-168.

Dincol, O. S., \& Yilmaz, A. (2013). The effect of environmental education on the pre-service teacher'affective tendency towards the environment and cognitive structure. Procedia Social and Behavioral Sciences, 106, 2704-2713.

Ercan, F., Tasdere, A., \& Ercan, N. (2010). Observation of cognitive structure and conceptual changes through word associations tests. Journal of Turkish Science Education, 7(2), 136-154.

Ersoy, A. F., \& Turkkan, B. (2010). Analyzing social and environmental issues elementary school students reflect in their cartoons. Education and Science, 35(156), 96-106.

Gokce, N., Kaya, E., Aktay, S., \& Özden, M. (2007). Elementary students' attitudes towards environment. Elementary Education Online, 6(3), 452-468.

Gunes, H., \& Gozum, A. I. C. (2013). Using the word association method or detection of the effect of ecology knowledge learned in primary education on readiness of 10th grade students. Journal of Research in Education and Teaching, 2(3), 252-264.

Hodges, W. J., Lamb, P., Brown, M. H., \& Foy, D. S. (2005). Assessment for all. Science Scope, January, 43-44.

Karasar, N. (2008). Scientific research method. Ankara: Nobel Publishing-Publishing.

Karatekin, K., \& Elvan, O. (2016). The cognitive schema of 8th grade students about democracy. Abant Izzet Baysal University Journal of Education Faculty, 16, (USBES Special İssue. II) 1405-1431.

Kaya, B., \& Akis, B. (2015). Determination of cognitive structure of geography students'on weather concept through word association test. Turkish Studies, International Periodical for the languages, literature and history of Turkish or Turkic 10(7), 557-574. (Publishing Turkish).

Kaya, M. F., \& Tasdere, A. (2016). An alternative measurement and assessment method for elementary turkish education: Word association test (WAT). Electronic Turkish Studies, 11(9).803-820.

Kaya, M. F., \& Tomal, N. (2011). Examination of the social sciences education program in the frame of sustainable development training. Journal of Educational Sciences Research, 1(2), 49-65. http://ebad - jesr.com/.

Kirtak, A. V. N., \& Demirci, N. (2012). Prospective teachers' levels of associating environmental problems with science fields and thermodynamics laws. Ahi Evran University Journal of Kirsehir Education Faculty (JKEF).13(3), $19-46$.

Kurt, H. (2013). Biology student teachers' cognitive structure on the concept of immunity. Dicle University Journal of Ziya Gökalp Education Faculty, 21, 242-264.

Kurt, H., Ekici, G., \& Aksu, O. (2013). Salt: The mental models of the prospectıve biology teachers. Journal of Research in Education and Teaching, 2(4), 244-255.

Meydan, A., \& Dogu, S. (2008). Evaluation of the views of the second grade primary school students on environmental problems according to some. Selcuk University Journal of Ahmet Kelesoglu Education Faculty, 26, 267-277.

Nakiboglu, C. (2008). Using word associations for assessing nonmajor science students' knowledge structure before and after general chemistry instruction: The case of atomic structure. Chemistry Education Research and Practice 9, 309-322. https://doi.org/10.1039/B818466F

Oner, A. F. (2015). Cognitive structures of elementary school students: What is science? European Journal of Physics Education, 6(2), 54-73.

Ozata, Y. E., \& Ozkan, M. (2016). Determining the perceptions of pre-service science teachers regarding environmental problems through word association. International Journal of Learning and Teaching, 8(3), 164-173. 
https://doi.org/10.18844/ijlt.v8i3.610

Ozatli, N. S. (2006). Determination of the topics perceived as difficult by the students in biology lessons and putting forth their cognitive structures about excretion system for consideration by new techniques. Balikesir University, Science Institute High School Mathematics and Science Teaching Department. Ph.D Thesis.

Ozatli, N. S., \& Bahar, M. (2010).Revealing students' cognitive structures regarding excretory system by new techniques. Abant İzet Baysal University Journal of Education Faculty, 10(2), 9-26.

Ozdemir, O. (2010). The Effects of nature-based environmental education on environmental perception and behavior of primary school students. Pamukkale University Journal of Education Faculty, 27, 125-138.

Ozmen, H. (2004). Learning theories in science teaching and technology assisted constructivist learning. The Turkish Online Journal of Educational Technology - TOJET. January, 3(1).

Perker, Z. S. (2011). The role of factory visits in the increase of material knowledge among architecture students: a methodological analysis. SAU Journal of Science, 15(1), 82-88.

Polat, G. (2013). Determination of the cognitive structures of year secondary school students through word association test techniques. Necatibey Faculty of Education Electronic Journal of Science and Mathematics Education, 7(1), 97-120. https://doi.org/10.12973/nefmed155

Secgin, F., Yalvac, G., \& Cetin, T. (2010). Perceptions of environmental issues through cartoons of primary 8 grade students'. International Conference on New Trends in Education and Their Implications.11-13 November, 2010 Antalya-Turkey.

Simsekli, Y. (2004). Sensitivity of elemantary schools to the environmental education activities for increasing environmental knowledge. Uludag University Journal of Education Faculty, XVII(1), 83-92.

Tanriverdi, B. (2009). Analyzing primary school curriculum in terms of sustainable environmental education. Education and Science, 34(151), 89-103.

Timur, S. (2012). Examining cognitive structures of prospective preschool teachers concerning the subject "Force and motion". Educational Sciences: Theory \& Practice - Special Issue. Autumn. 3039-3049.

Uzun, N., Ozsoy, S., \& Keles, O. (2010). Pre-service teachers' views about the concept of biodiversity. Research Journal of Biology Sciences, 3(1), 85-91.

Yalvac, G. H. (2008). Effect of cooperative learning approach on intellectual structure of teacher candidates regarding environment. Unpublished Master's Thesis. Abant İzzet Baysal University Institute of Social Sciences: Bolu.

\section{Copyrights}

Copyright for this article is retained by the author(s), with first publication rights granted to the journal.

This is an open-access article distributed under the terms and conditions of the Creative Commons Attribution license which permits unrestricted use, distribution, and reproduction in any medium, provided the original work is properly cited. 